\title{
Life limits and biomorph formation along polyextreme gradients in the geothermal area of Dallol (Ethiopia)
}

P. LÓPEZ-GARCÍA ${ }^{1 *}$, J. Belilla ${ }^{1}$, K. BENZERARA ${ }^{2}$, J.M. LÓPEZ-GARCÍA ${ }^{3}$, L. JARDILLIER ${ }^{1}$, P., G. REBOUL ${ }^{1}$, P. BERTOLINO $^{1}$, A. I. LÓPEZ-ARCHILLA ${ }^{4}$ AND D. MOREIRA ${ }^{1}$

${ }^{1}$ Ecologie Systématique Evolution, CNRS, Université ParisSaclay, Orsay, France (*correspondence :puri.lopez@upsud.fr)

${ }^{2}$ Institut de Minéralogie, de Physique des Matériaux et de Cosmochimie, CNRS, Sorbonne Université, Paris, France ${ }^{3}$ Instituto Geológico y Minero de España, Palma de Mallorca, Spain

${ }^{4}$ Dpt. Ecologia, Universidad Autonoma de Madrid, Spain

Located at the North of the Danakil salt desert, Dallol is a halo-volcanic system showing intense degassing and hydrothermal activity producing highly concentrated brines $(>35 \%$ w/v) with extremely low pH $(<0)$ and high temperature (up to $110^{\circ} \mathrm{C}$ )[1]. Although microbial life has adapted to various individual extreme conditions, organisms simultaneously adapted to those polyextreme conditions remained to be discovered. Our combined environmental 16S/18S rRNA-gene metabarcoding, cultural approaches, fluorescence-activated cell sorting, scanning electron microscopy and chemical analyses support the existence of two major physicochemical barriers preventing active life along such unique polyextreme gradients in the DallolDanakil area. These barriers are defined by: i) high chaotropicity-low water activity in $\mathrm{Mg}^{2+} / \mathrm{Ca}^{2+}$-dominated brines and ii) hyperacidity-local salt combinations [2]. However, we detect microbial life in the less polyextreme sites at the Dallol dome and Danakil depression surroundings, which is dominated by highly diverse ultrasmall archaea widely distributed across phyla with and without previously known hyperhalophilic members. We detect active silica encrustment/fossilization of cells but also abundant abiotic biomorphs of varied chemistry, raising warnings for the interpretation of morphological biosignatures on Earth and beyond [2]. Indeed, active wind dispersal of microbes from the neighboring salt pan combined with misinterpretation of abiotic biomorphs as fossilized microbes [2] in a highly dynamic mineral precipitation environment [3] can explain recent claims about the occurrence of Nanohaloarchaeota in the Dallol brines. Our results point to the absence of life from some polyextreme sites in the presence of liquid surface water on Earth and should help to circumscribe habitability.

[1] López-García et al. (2020) Front Earth Sci 7, 351. [2] Belilla et al. (2019) Nat Ecol Evol 3, 1552-1561. [3] Kotopoulou et al. (2019) ACS Earth Space Chem 3, 90-99. 